\title{
ANÁLISE DISCURSIVA DA BNCC: CONSTRUÇÃO OU (DES)CONSTRUÇÃO DA EDUCAÇÃO ESCOLAR PÚBLICA BRASILEIRA?
}

\author{
Ivanise Jurach ${ }^{*}$ \\ Taise Neves Possani ${ }^{* *}$
}

RESUMO: O interesse para desenvolver este trabalho emerge a partir da aprovação da Base Nacional Comum Curricular (BNCC) instituída como referência para as escolas de educação básica brasileiras. Embora ela seja uma conquista em termos de respeito às leis que regem a educação brasileira, também podemos afirmar que há muitas questões não explícitas dentro dela que só conseguimos compreender por meio de uma leitura reflexiva. Iremos analisar algumas passagens deste documento sensibilizando para a produção dos efeitos de sentido que se produzem em determinados contextos de uso da língua. Para isso, tomamos como referencial teórico a Análise do Discurso (AD) de linha francesa, mobilizando noções como ideologia, discurso e materialismo histórico e autores como Michel Pêcheux e Eni Orlandi. Nossas análises demonstram que o político da língua entra em jogo e opera com significados diferentes daquilo que parece ser quando se faz uma leitura superficial deste documento regida pelo senso comum. Desse modo, organizamos a estrutura deste trabalho da seguinte forma: após as considerações introdutórias, destacamos algumas noções teóricas da $\mathrm{AD}$ que serão abordadas ao longo da pesquisa. $\mathrm{Na}$ sequência, resumimos a parte histórica de elaboração dos documentos oficiais da educação que antecedem à BNCC ressaltando que a língua está inscrita na história. Partimos, então, para as análises propriamente ditas, chegando a uma breve conclusão desses estudos.

PALAVRAS-CHAVE: Base Nacional Comum Curricular; Educação escolar; Efeitos de sentido; Ideologia; e Político da língua.

\footnotetext{
* Mestre em Letras pela Universidade Federal de Santa Maria (UFSM).

** Mestre em Letras pela Universidade Federal do Rio Grande (Furg). Professora da Universidade Regional do Noroeste do Estado do Rio Grande do Sul (Unijuî).
} 


\section{Considerações iniciais}

O presente trabalho tem por objetivo investigar a proposta de ensino divulgada a partir da aprovação da Base Nacional Comum Curricular (BNCC) através de estudos da Análise do Discurso (AD) de linha francesa, pois observamos que nesse documento há referência a expressões como: aprendizagens essenciais, princípios éticos, políticos e estéticos, formação humana integral, competências e educação integral. Sendo assim, compreendemos que o funcionamento da língua e dos efeitos de sentido que se produz em passagens desse documento interpelam o sujeito a acreditar em uma proposta de educação "carregada" por interesses políticos e econômicos, os quais se disfarçam através do uso da linguagem, pela escolha das palavras.

A curiosidade por esta pesquisa surge através de nossa posição-sujeito como professora que vem acompanhando este processo de escrita/reescrita e de imposição, sendo "orientadas" a pôr em prática os conceitos desta Base. Os saberes que emergem na leitura da BNCC estão atravessados por várias tomadas de posição, já que ela foi construída coletivamente. Cada sujeito opera a partir do seu posicionamento político naquilo que concerne à área da educação, há um atravessamento de conflitos em relação ao que se acredita por educação. Ressaltamos também que há embates políticos e ideológicos que norteiam a elaboração desta última versão da BNCC e é justamente isso que nos "incomoda" e suscita perguntas se de fato estamos contribuindo para o "conhecimento poderoso" ou para o "conhecimento dos poderosos" (cf. YOUNG, 2007).

Desse modo, nossa preocupação é analisar o materialismo histórico que constitui a formulação desse documento e de que modo esses saberes operam com discursos que interpelam o sujeito em ideologia(s), pois enquanto professoras também somos levadas a acreditar nessa proposta e submissas a um sistema político que determina e "orienta" a trabalhar conceitos, o qual não prevê questionamentos ou resistência, ainda que o documento destaque que há autonomia por parte do sujeito professor em trabalhar com esses conceitos em sala de aula. No entanto, ao se impor uma uniformização de ensino já não há autonomia e é através dessa inquietude pedagógica que buscamos interpretar, analisar e 
investigar o que realmente está dito e implícito na BNCC. E outro fator a ser considerado é o caminho percorrido até a sua elaboração, será que esta última versão segue na mesma linha ideológica que as duas primeiras?

Também iremos buscar pistas linguísticas para compreender o funcionamento discursivo que rege esta nova proposta. Quais são, de fato, os discursos que emergem dentro do contexto de elaboração desse documento? Por que há necessidade em "renovar" o currículo escolar? Será que há possibilidades de introdução de um pensamento que permita desenvolver a educação brasileira ou, ao contrário, que está mascarada por um objetivo de "diminuir" a habilidade de interpretar e refletir o papel de cidadão dos nossos estudantes? Seria para colaborar na construção de uma educação pública de qualidade ou para desconstruí-la?

Ao ler a apresentação da BNCC, no primeiro parágrafo, já nos damos conta de um equívoco quando o ministro da educação ${ }^{1}$ do Brasil nos compara a uma proposta mundial, afirmando que há um alinhamento com os sistemas mais qualificados do mundo. Quem trabalha em escolas públicas brasileiras conhece a realidade desses locais, ainda há muito para melhorar e quem dirá chegar a um nível que se possa comparar com os melhores índices mundiais. A educação em turno integral, por exemplo, é uma realidade em prática nos países que lideram a educação, entretanto, se pensar aqui no Brasil, essa prática poderia funcionar? Afinal, há espaço físico adequado dentro das nossas escolas para comportar todos os estudantes desde a educação infantil até o final do ensino fundamental em dois turnos? Há recursos para manter o aluno dentro da escola? (lanche, almoço, café da tarde, etc.). E ainda: há projetos educacionais consistentes com as necessidades formativas de um turno integral?

E, além da falta de um espaço físico adequado para comportar turno integral dentro das escolas públicas brasileiras e também pela falta de investimentos para a educação por parte dos governos, tanto federal quanto estadual ou municipal, temos outros entraves que

1 O ministro da educação em 2018 era Mendonça Filho. 
impossibilitam aplicar essa prática: a falta de profissionais qualificados para esse fim e de um projeto bem fundamentado e planejado para permitir aos estudantes que permaneçam na escola envolvidos pelo conhecimento. Para isso, teria que se pensar em práticas diversificadas, como, por exemplo, esportes, músicas, teatro e dança, as quais poderiam constituir um currículo ampliado e voltado para a formação humana cidadã e não pensada apenas para uma formação de ingresso ao mercado do trabalho ou para uma mecanização do ensino que considera apenas a cientificidade do conhecimento.

Pensando nessas questões, de acordo com os estudos de Masschelein (2014, p. 2627), é explícito que há influência da elite sobre a escola desde os tempos da Grécia quando a inventaram. Ele afirma que "a invenção do escolar pode ser descrita como a democratização do tempo livre", portanto, tempo livre representa desprezo para aqueles que almejam continuar no poder, dominando sujeitos pela falta do conhecimento. No imaginário deles, os únicos sujeitos que podem ter o direito de acesso ao conhecimento são grupos que pertencem a este lugar de elite, os demais não podem sair daquele lugar de inferioridade, de submissão, porque isso mudaria a ordem da sociedade, ou, nas palavras do autor "para aqueles que estavam satisfeitos em permitir que a organização desigual da sociedade continuasse sob os auspícios da ordem natural das coisas, essa democratização do tempo livre era uma pedra no sapato". Logo, a escola em turno integral não é prioridade de uma sociedade desigual como o Brasil. Se isso acontecesse, poderia transformar o pensamento e provocar uma "quebra" no sistema vigente.

Em nosso ponto de vista, há uma leitura equivocada e muito drástica nesse primeiro parágrafo de apresentação da BNCC (p. 5), onde se escreve que: "ao homologar a Base Nacional Comum Curricular (BNCC) para a Educação Infantil e o Ensino Fundamental, o Brasil inicia uma nova era na educação brasileira e se alinha aos melhores e mais qualificados sistemas educacionais do mundo". Tal afirmação, evidencia referência ao político da língua. Vale ressaltar que o político a que nos referimos não está voltado para a política, mas, conforme o campo epistemológico da $\mathrm{AD}$, é compreendida como tomadas 
de posição que provocam embates, como jogo de forças que vem à tona na sociedade e se concretizam por meio de discursos (cf. PÊCHEUX, 2007).

Enquanto sujeitos professoras, inscritas e identificadas pelo espaço escolar, gostaríamos de registrar nossa inquietude diante da leitura e análise da BNCC. Destacamos que, neste trabalho, pontuamos um olhar de sujeito professora e também de sujeito inscrito na área de Letras. É por meio desse olhar que argumentamos e trazemos passagens que permitam observar e pensar o posicionamento que há nesse documento, sensibilizando para muitas questões que parecem não produzir efeitos negativos, mas, que a partir de uma leitura apoiada em noções teóricas da $\mathrm{AD}$, podemos refletir que há uma tentativa de desqualificar a educação básica.

Devido à amplitude dos registros e pelo fato da BNCC estar dividida em etapas (educação infantil, séries iniciais do ensino fundamental $\left(1^{\circ}\right.$ ao $5^{\circ}$ ano $)$ e séries finais $\left(6^{\circ}\right.$ ao $9^{\circ}$ ano), traçamos um recorte para respaldar nossos argumentos do funcionamento discursivo com o qual ela opera. Delimitamos, então, o corpus de pesquisa, na parte introdutória e na área de linguagens das séries finais do ensino fundamental $\left(6^{\circ}\right.$ ao $9^{\circ}$ ano) já que nosso interesse é em relação ao uso da linguagem. Não queremos dizer que as outras partes desse documento não estejam interligadas com nossa investigação, mas, para realizar a análise discursiva é preciso selecionar passagens.

Para compreender esse processo, iniciamos com algumas noções teóricas da AD que abordamos no decorrer desta pesquisa. Em seguida, fazemos um breve levantamento histórico da educação brasileira e de como ela se modifica com o passar dos tempos, quais são os dizeres e saberes presentes nos documentos oficias anteriores à BNNC que permitiram chegar até a sua construção. E, por último, desenvolvemos as análises de partes selecionadas desse documento.

\section{Noções teóricas da análise do discurso}

A Análise do Discurso é uma teoria de estudos voltada para a linguagem, para a produção dos efeitos de sentido que as palavras “evocam” em diferentes contextos de uso 
da língua. O início dela ocorre no final dos anos 60, na França, constituindo-se por três áreas do saber: a Linguística, o Marxismo e a Psicanálise. Neste embate de discursos atravessado por questões ideológicas é que Michel Pêcheux, fundador da teoria, observa o funcionamento da língua, a maneira como ecoam as palavras e como elas repercutem em tomadas de posição. No começo, as possibilidades de estudo da teoria se restringiam ao campo da política, o objeto de análise era o discurso político, mas, com o passar dos tempos, a partir de discussões em torno das noções com as quais a $\mathrm{AD}$ opera, abriram-se outras possibilidades de interpretação e análise.

No Brasil, a referência em estudos da $\mathrm{AD}$ é a professora $\mathrm{Dr}^{\mathrm{a}}$ Eni Orlandi, precursora desses estudos no campo da Linguística brasileira. Segundo ela (1999), não há esgotamento de sentidos em Análise do Discurso, o que se busca compreender é a língua em movimento que permite circular com diferentes formas de produzir significados. No caso da BNCC, os sentidos que se produzem no texto de sua elaboração estão marcados por tomadas de posição identificadas por uma ideologia. É a ideologia que determina a identificação do sujeito com certos discursos e não com outros, tendo em vista que "as ideologias não são feitas de ideias, mas de práticas" (PÊCHEUX, 1997, p. 144). Em outras palavras, cada lugar social comporta uma ideologia específica e isso implica na tomada de posição.

Outra noção teórica que mobilizamos são as condições de produção, elas determinam aquilo que pode ou não ser dito em determinado contexto. Por isso, os efeitos de sentido que se produzem em diferentes discursos para uma mesma palavra funcionam de diferentes maneiras, ou seja, uma mesma palavra poderá remeter a significados diferentes, como é o caso das palavras ética e estética que analisamos. No processo de elaboração da BNCC se considera o discurso em prol da educação, verificamos que há trechos onde se escolhem palavras para que o sujeito não pense diferente daquilo que poderia ser, entretanto, em $\mathrm{AD}$, não existe controle de sentidos, cada sujeito interpreta conforme a sua inscrição na história tomada pelo uso da língua (cf. ORLANDI, 1999). Desse modo, pensar 
em controlar os sentidos é ilusão e mesmo que a BNCC tente disfarçar o seu posicionamento via linguagem, não há limites de sentido, a interpretação foge ao controle de quem produz a escrita.

Diante das considerações que mobilizamos até o presente momento, compreendemos que são vários os discursos que circulam entre os sujeitos, principalmente quando se trata da educação pública brasileira. Cada um desses discursos está constituído por diferentes concepções e modos de interpelação, mas serão as Formações Discursivas (FDs) que "conduzirão [o sentido] a um caminho" e não a outro, pois Pêcheux (1997, p. 261) afirma que "a interpelação do indivíduo em sujeito de seu discurso se realiza pela identificação do sujeito com a formação discursiva que o domina, identificação na qual o sentido é produzido como evidência pelo sujeito e, simultaneamente, o sujeito é produzido como causa de si".

Observamos que Pêcheux destaca a importância da FD em relação à constituição dos efeitos de sentido. O indivíduo precisa identificar-se com determinados saberes para se constituir enquanto sujeito discursivo e é a partir dessa identificação que o sujeito se posiciona e interpreta os discursos que o cercam. O sujeito pode até ser tomado por outros saberes advindos de diferentes FDs com as quais ele não está inscrito socialmente, porém a base para que o sujeito se inscreva em uma FD e não em outra é a ideologia, pelo modo singular como cada sujeito é interpelado. Os efeitos de sentido são produzidos conforme as atribuições imaginariamente dadas pelo sujeito às coisas que lhe são representadas discursivamente.

Por esse viés, a historicidade também é constitutiva do sujeito, ela faz parte do processo da tomada de posição, pois a língua, a ideologia e a história são determinantes na produção dos efeitos de sentido, o que implica em afirmar que os discursos estão materializados pela língua, as palavras se movimentam através da língua inscrita na história e os sentidos podem não ser os mesmos em diferentes momentos, em diferentes situações discursivas. Mesmo que as palavras carreguem consigo uma memória, isso não garante que o sentido fique estabilizado, fixo, porque os interlocutores serão outros, tendo em vista as 
condições sócio-históricas em que os discursos são produzidos, pois “sem história não há sentido, é a inscrição da história na língua que faz com que ela signifique" (ORLANDI, 1994, p. 52).

Essas considerações permitem compreender que, se os efeitos de sentido não são “estáveis", a ideologia também não é “estável” ou "estática”, ela pode mudar através da história, uma vez que uma mesma FD pode estar ideologicamente significando de modo diferente em distintos períodos históricos, de acordo com os discursos que são permitidos enunciar em dado momento.

Desse modo, também funciona a noção de apagamento (cf. Pêcheux, 2007), a qual afeta de tal modo o sujeito fazendo com que ele "apague" de sua memória discursiva a origem dos dizeres com os quais se identifica, tomando esses dizeres, então, para si e pronunciando-os como se eles tivessem sido originados em si. O sujeito não tem controle sobre todas as possibilidades de (re)tomada dos discursos. Na verdade, o sujeito é tomado pela ilusão de ser o primeiro a pronunciar tais discursos, quando ele está apenas (re)produzindo algo que já foi dito por outro alguém em outro momento.

As palavras também têm influência do processo sócio-histórico, o qual mobiliza diferentes sentidos a partir dos acontecimentos históricos. Uma mesma palavra pode não remeter ao mesmo sentido em diferentes situações de enunciação, tendo em vista quem são os interlocutores e o lugar de onde são pronunciadas tais palavras, já que elas dependem da ideologia que as sustenta. Se a ideologia não é “estável”, as palavras também não se "estabilizam" em um único efeito. No entanto, apesar de as palavras significarem de maneira diferente, elas pertencem a uma mesma ordem discursiva tendo em vista o fato de que não são todos os sentidos possíveis já que eles dependem do modo pelo qual os sujeitos se relacionam de modos singulares com esses saberes.

Após essa breve apresentação de algumas noções teóricas da AD em que buscamos respaldo para o nosso trabalho de pesquisa, passamos para o item seguinte, o qual aborda alguns momentos históricos importantes do campo da educação brasileira, desde a 
chegada dos portugueses até a atualidade, e de que forma isso repercute na elaboração da BNCC.

\section{Contextualização do ensino no Brasil}

Os humanos se inventaram e, com isso, necessitam continuar se inventando, com o que vão constituindo o mundo humano. (BOUFLEUER \& FENSTERSEIFER, 2018)

Somos uma nação marcada pela exploração de outros povos e isso implica na maneira como se pensa a educação brasileira desde a chegada dos portugueses até os dias atuais. Quando os portugueses vieram ao Brasil, em 1500, trouxeram consigo uma doutrina escolar voltada para princípios religiosos, haja vistas que nesta época ocorria o protestantismo na Europa, momento de ruptura do Estado com a Igreja. Isso permitiu aos portugueses que deslocassem o seu interesse para cá, a partir da fundação da Companhia de Jesus que tinha por objetivo pregar uma doutrina religiosa, o Catolicismo. (cf. TEIXEIRA \& CORDEIRO, 2008).

Desse modo, os índios foram submetidos a um sistema de dominação religiosa, a educação estava a serviço do comando da Igreja Católica. As escolas se tornam monopólio e contribuem para a difusão do pensamento europeu. Emerge uma ideologia cristã católica que passa a circular pelo território brasileiro e interpela os sujeitos a acreditar nos discursos da Igreja. Apaga-se o que vinha antes deste momento, que o índio possuía suas próprias crenças e sua história, é como se o Brasil passasse a existir somente com a chegada dos portugueses. A imagem que veiculava sobre o índio até pouco tempo atrás era do selvagem, daquele que precisava ser "educado" e "civilizado". Essa imagem vem à tona quando lemos a Carta de Pero Vaz de Caminha. Nela encontramos descrições para o povo que aqui habitava como "gente desprovida de conhecimento, sem fé, nem lei, nem religião" (1999).

Esse sistema de ensino durou até 1759, quando foi feita a Reforma Pombalina, expulsando os jesuítas do território brasileiro e excluindo a Companhia de Jesus. Tomada pelas ideias iluministas do continente europeu, essa reforma tinha como visão desenvolver 
o Brasil conforme o avanço dos países europeus. O Estado passa a assumir o papel da educação que até aquele momento estava sob comando da Igreja. Por um lado, se esse pensamento previa desenvolver a nação, o que acontece é um sistema inverso, porque não havia professores qualificados para trabalhar de acordo com as ideias iluministas, os únicos que possuíam habilidades para ensinar eram os padres jesuítas, que justamente foram "proibidos" de continuar o seu trabalho pedagógico.

Através dessa intervenção na área da educação, podemos afirmar que o Brasil está marcado por diversas ideologias desde os tempos de colonização, não são recentes as reformas que vêm ocorrendo no ensino básico. Elas estavam voltadas para interesses políticos e com o objetivo de se trabalhar uma ideologia específica, a serviço dos interesses de Portugal ou do continente europeu e não consideravam a realidade local brasileira.

Ressaltamos que o período iluminista na Europa estava muito avançado em relação àquele início do período que surge no Brasil e isso acaba gerando outro problema: surgem conflitos no modo de conceber a educação que vinha seguindo uma ordem religiosa. Essa ruptura causa transtorno, pois no Brasil, já tinha atrasos na educação e os avanços se apresentaram de forma muito lenta, mais ou menos um tempo de 30 anos para se adaptar ao modelo de ensino proposto por Marquês de Pombal. Conforme Seco \& Amaral ${ }^{2}$

\begin{abstract}
É muito interessante perceber por quais vias o iluminismo implantou-se no Brasil. É justamente através da política imperial de racionalização e padronização da administração de Pombal que a educação passou para as mãos do Estado, mas essa educação que passou a ser pública, não se faz para os interesses dos cidadãos. Ela serviu aos interesses imediatos do Estado, que para garantir seu status absolutista precisa manter-se forte e centralizado nas mãos e sobre comando de uns poucos preparados para tais tarefas... iluminismo no contexto da colônia brasileira tratou-se, na verdade do engrandecimento do poder do Estado e não das liberdades individuais.
\end{abstract}

No momento em que o Brasil poderia estar caminhando em uma única direção norteadora da educação, emerge um outro contexto sócio-histórico que “quebra” a visão

${ }^{2}$ Ver em referências a fonte. Na página de pesquisa, não consta ano de publicação e páginas. 
propagada pelo iluminismo de Pombal. Em 1822, com a chegada da família real ao Brasil, muda-se outra vez a perspectiva de ensino público. Agora, a época do Brasil Império, onde surgem as primeiras instituições de ensino superior no Brasil. Os ideais iluministas são substituídos pelos ideais capitalistas. Desse momento em diante, a educação passa a estar a serviço do capital, da produção de bens materiais e da mão-de-obra trabalhadora. Começa um período de educação para a elite, mercadoria de poder influenciada pelo capital (cf. NASCIMENTO, 2006).

As instituições de ensino superior tinham como propósito apenas a formação necessária para exercer a profissão de médico, advogado, jornalista... As licenciaturas ainda não eram objetivo. Para dar aulas no ensino básico, bastava apenas uma formação mínima, o que hoje equivale ao ensino fundamental ( $9^{\circ}$ ano). Assim, podemos observar dois posicionamentos distintos no que tange à valorização da educação no período imperial: uma disparidade entre o ensino público e o ensino privado. Quem tinha posses estudava em grandes colégios, instalados nos grandes centros com todo o material disponível e quem não tinha condições para ir adiante com os estudos, ficava apenas com o mínimo de instrução ofertada por profissionais não preparados.

Mesmo que se percebesse o descaso com o público, que não haviam investimentos e formação de professores para melhorar o ensino brasileiro, pouco se fez nesse período imperial para melhorar a educação básica pública. Se investiu mais em construir escolas privadas. Em nosso entendimento, começa, a partir deste momento, a se formar o imaginário de que quem podia estudava, quem não possuía bens, não precisava estudar, acabava se tornando mão-de-obra e aceitava a sua condição, ainda que resistisse.

A fase do Brasil Império “acaba” em 1889, na República Velha. É importante registrar que "não é pelo fato que a República tenha sido proclamada em 1889, que a vida econômica e social se transformou a partir daí, pelo contrário, ela seguiu da mesma forma, mudando somente o regime político" (CLARK, 2003). Isso significa que na área da educação, ainda permanecem muitas questões atrasadas, há um conflito de ideias entre diferentes 
visões e também continua prevalecendo a separação entre as classes sociais. Somente quem possuía capital "tinha direitos" a se formar em universidade.

Os Republicanos buscam respaldo nas ideias positivistas de Augusto Comte propagadas pela Europa para desenvolver a educação e as ciências. Novamente, há uma cópia de outros países, desconsidera-se a realidade local em prol de uma maioria europeia, como se tudo o que desse certo na Europa pudesse também funcionar aqui no Brasil.

Nesse período, foram feitas várias reformas no ensino, destacando-se a criação dos Grupos Escolares, divididos em ensino primário (até a $4^{\mathrm{a}}$ série) e ensino secundário $\left(5^{\mathrm{a}}\right.$ a $8^{a}$ série). Essa criação, de acordo com Clark (id.)

[...] alterou o curso de história do ensino público primário no país, através de seus projetos de organização curricular e administrativa, a criação dessa modalidade de ensino, apresentava um ensino seriado onde os alunos eram distribuídos homogeneamente sob a orientação de um só professor, cujo método seguido era o intuitivo. Isso criou novas relações de poder dentro das escolas, e a partir de 1894, se criava também o cargo de diretor escolar, além disso, renovou os saberes escolares, sendo também proposto uma nova estrutura arquitetônica, construída especificamente para esse fim.

Essa citação inquieta e permite salientar que havia interesses em formar "sujeitos iguais". Não se pensava as diferenças e, além disso, determinava-se que todos estivessem numa mesma situação de aprendizagem, remetendo-nos a uma ideia behaviorista, onde todos estudavam da mesma forma e o método aplicado era o decorativo, ou seja, se decorava conceitos e não se questionava, não havia abertura para o conhecimento, se aprendia e pronto, era assim que deveria ser porque a ciência assegurava isto, tudo era motivo de explicação pelo método científico.

Podemos refletir sobre como era o ensino público na República Velha em concomitância com o Brasil Império a partir de uma música inglesa, da banda Pink Floyd "Another Brick in the Wall' (outro tijolo na parede). Essa música compara os estudantes a tijolos manipulados por um sistema de ensino vigente. O propósito não era desenvolver a aprendizagem, mas, sim, manipular sujeitos através do conhecimento, o qual não os libertava, não possibilitava pensar ou refletir na sua condição. 
Essa política de educação é substituída em 1930 pela era Vargas, do presidente Getúlio Vargas. Nessa época, surge o Manifesto dos Pioneiros da Educação Nova, proposta elaborada por professores, dentre os quais se destacam Pascoal Lemme, Anísio Teixeira e Fernando Azevedo. Nesse momento surge pela primeira vez a preocupação em formar professores qualificados, se admite a necessidade de introduzir cursos voltados para o trabalho pedagógico e também se compreendia que era importante mudar o sistema de educação vigente. O objetivo dos Pioneiros da Educação era permitir que o sujeito se libertasse por meio do conhecimento. (cf. MACHADO; KASTELIC) ${ }^{3}$.

Nesse sentido, Pascoal Lemme teve importante desempenho nesse processo, pois ele se deu conta de que era preciso investir em formar professores para desenvolver a educação e para conseguir melhorar o nível de ensino brasileiro rompendo com as questões de poder que até aquele momento determinavam como deveria ser o ensino nas escolas. O Manifesto dos Pioneiros da Educação Nova “expressava os princípios básicos da educação moderna e científica, a gratuidade, a obrigatoriedade do ensino, a laicidade, a coeducação e o Plano Nacional de Educação" (MACHADO; KASTELIC, id.).

Chama atenção que em 430 anos de história da formação do povo brasileiro é recém deste momento em diante que começa a se pensar em mudanças significativas para a educação brasileira, iniciando uma discussão sobre o que realmente poderia ser feito para mudar as bases curriculares dentro das escolas. Além disso, é a primeira vez que o debate sobre educação é feito por estudiosos da própria educação ou por professores não conformados com o sistema vigente que até então determinava os rumos da história.

Conforme afirmamos anteriormente, a educação depende de uma visão política. Infelizmente o Manifesto dos Pioneiros da Educação Nova, visto como um marco importante para a renovação do sistema educacional vigente, perde a sua força a partir de 1964 com a implantação da ditadura militar no Brasil, a qual estava influenciada por uma visão de educação repressiva. O governo era responsável por controlar o ensino e também podia

${ }^{3}$ Não consta ano de publicação e página. Cf. em referências. 
censurar, proibir de se estudar certos assuntos. Os sujeitos que protestavam contra essa forma de governo autoritário sofriam as consequências, não tinham direito de manifestação, o que se sustenta pelo Decreto do Ato Institucional n.5 (AI-5) pelo então presidente Costa e Silva em 1968, sendo uma das leis mais rígidas daquele momento. Por isso, a educação nesse período teve "retrocessos", já que a escola estava à mercê de uma ditadura. Parece que estamos diante de uma semelhança ao que hoje está em tramitação no Congresso, a Lei do Escola sem Partido.

De acordo com Saviani (2005), na década de 1970 a educação passa a servir o capital, com o objetivo de formar mão-de-obra, qualificar a força de trabalho e não o intelecto dos estudantes. Assim, seria mais fácil explorá-los, afinal, quanto menos desenvolver o pensamento crítico será mais fácil subordinar sujeitos ao sistema capitalista.

Os manifestos de ruas começam a surtir efeito e os movimentos de base democrática passam a modificar novamente o cenário brasileiro a partir da década de 1980, quando se conquista o direito pela democracia. Em 1985 é eleito, através do voto, o presidente Tancredo Neves. No entanto, devido ao seu falecimento antes de assumir a Presidência, é o seu vice José Sarney quem assume de fato. Em 1988, promulgada a Constituição Brasileira, é que se retoma a pauta de discussões acerca da necessidade de se pensar os rumos da educação.

É desse momento em diante que podemos perceber o engajamento da sociedade em luta e defesa de uma escola pública de qualidade para todos, sem distinção de classes ou posição social. Além da Constituição de 1988, outro referencial que contribui para avançar a educação no sentido de formar sujeitos cidadãos críticos e ativos é a Lei 9394/96, a Lei de Diretrizes e Bases (LDB). A partir desse contexto sócio-histórico, surgem outras referências que também orientam a elaboração e construção da BNCC. Podemos citar: os Parâmetros Curriculares Nacionais (PCNs) de 1997, Diretrizes Gerais para a Educação Básica de 2010 e o Plano Nacional da Educação de 2014 a 2024.

Destacamos que não se esgota nesse simples resumo as lutas e os conflitos em prol da educação pública, mas, traçamos esse levantamento enquanto possibilidade de melhor 
compreender o quanto a linguagem é multifacetada e carregada de sentidos ao se construir leis que norteiam os princípios da área da educação. Não há como desconsiderar que a política é um dos entraves ou um dos alavanques que impulsiona a baixa ou alta qualidade da educação. Todos os documentos que surgiram antes da BNCC, ecoam efeitos de sentido e divulgam uma ideologia voltada a interesses políticos e de política.

A seguir trabalhamos com uma análise de palavras frequentemente marcadas no texto da BNCC e como elas produzem sentidos e interpelam o sujeito em ideologia.

\section{Sobre os princípios éticos, políticos e estéticos e a formação humana integral}

Iniciamos pela parte em que a BNCC aborda quais são os seus princípios orientadores: “éticos, políticos e estéticos”, os quais “visam a formação humana integral” (p. 7). Podemos compreender que esses três princípios juntos produzem um efeito de sentido que nos remete a vários campos de saber. Por exemplo, a estética não será interpretada da mesma forma por sujeitos que ocupam posições diferentes, se perguntar a um professor de arte o que significa estética, para ele talvez será o belo ou o defeito de um quadro, de uma pintura, de algum local, etc. Já para um profissional da área da saúde, um médico ou um enfermeiro, a estética poderá estar vinculada à noção de corpo, a beleza ou à imperfeição da forma física. E na BNCC o sentido produzido para estética, dentro da educação, está voltado para uma normativa, é de caráter regido por lei. São poucas as referências à estética, mas, do modo como ela aparece no texto, inferimos que se relaciona à produção do conhecimento limitado, aquele que só considera um olhar para as situações de aprendizagem perfeitas.

Isso significa dizer que há várias possibilidades de interpretar uma mesma palavra, dependendo da posição-sujeito a que estará sendo dita. Ela pode remeter tanto a sentidos próximos quanto distantes um do outro. Além disso, a sequência com que se organiza os dizeres do enunciado demonstra que estética não é o principal, não é o mais importante orientador do documento. Pela ordem, o primeiro a guiar as questões da BNCC, seria o princípio ético e o segundo o político. Estando o princípio estético como última instância. 
No dicionário Houaiss (2009, p.847), a definição de ético é “concernente ou próprio da ética”. Assim, buscamos a descrição dada para ética (id.), que afirma ser

1 parte da filosofia responsável pela investigação dos princípios que motivam, distorcem, disciplinam ou orientam o comportamento humano, refletindo a respeito da essência das normas, valores, prescrições e exortações presentes em qualquer realidade social. 2 Conjunto de regras e preceitos de ordem valorativa e moral de um indivíduo, de um grupo social ou de uma sociedade.

Dentro do contexto em que se aplica, sendo um documento oficial que rege o currículo da educação brasileira, acreditamos que o ético se refere ao que não caberia trazer para debate, isto é, conteúdos que podem ou não podem ser trabalhados em uma sala de aula. Remete-nos a uma situação de censura já que se há princípio ético, quer dizer que há um regulamentador das propostas e do trabalho pedagógico. De acordo com Hermann (2014, p. 92), “as éticas que exerceram influência no pensamento pedagógico tendem a excluir a ambiguidade, a diferença, aquilo que não se enquadra nas normas, não pondo em evidência a alteridade”. Tal argumento propõe inferir que a ética não abre o espaço para o outro, para aquele que é diferente ou que pensa diferente do padrão "normal" de uma sala de aula.

Claro que não devemos deixar de considerar que a ética, em educação, não é apenas isso, em grande parte, sim, ela limita o conhecimento e reduz a possibilidade de se pensar no coletivo, entretanto, a ética também é importante quando voltada à postura profissional, às condutas humanas que regem uma vida em sociedade. Enfatizamos que nosso olhar é de analistas da produção dos efeitos de sentido que as palavras produzem no documento, a materialidade linguística que elas nos remetem e não tomamos esses efeitos como prontos e acabados, isto é, não estamos excluindo o grau de importância da ética para a educação escolar ou afirmando que ela não seja fundamental para o desenvolvimento humano.

Essa é uma das falhas que emergem no documento, há um contraponto com a proposta que ele descreve que seria a de dar autonomia e liberdade à escola e ao professor para trabalhar com os conceitos de cada etapa e de cada componente curricular do ensino 
fundamental considerando as diferenças, o lugar do outro. Se retomar o conceito do dicionário, acreditamos que a ética, assim como proporciona a liberdade e autonomia para o sujeito, também poderá estar regida por um conjunto de regras "limitadoras" do conhecimento, as quais não permitem ao sujeito sair da sua condição de assujeitado à ideologia que o interpela e que o constitui enquanto indivíduo da sociedade.

São os equívocos da língua que vem à tona na elaboração da BNCC. Segundo Orlandi (1999, p. 37), “é porque a língua é sujeita ao equívoco e a ideologia é um ritual com falhas que o sujeito, ao significar, se significa". Consideramos, então, que por ser um documento formulado coletivamente e tendo equívocos na língua, os sujeitos que estão envolvidos nesse processo de elaboração do documento, provavelmente estejam tomados pelo desejo inconsciente de que a educação tenha limites de conhecimento, seja subordinada a um sistema que restringe o pensamento crítico.

É nesse sentido que a educação, da maneira prevista no documento, estaria a serviço do conhecimento dos poderosos. Young (2007, p. 1294) afirma que "o conhecimento dos poderosos é definido por quem detém o conhecimento", já o "conhecimento poderoso refere-se ao que o conhecimento pode fazer, como, por exemplo, fornecer explicações confiáveis ou novas formas de se pensar a respeito do mundo". Este autor traz à baila uma importante reflexão sobre a história do processo de instituir currículos escolares: há muito tempo que a elaboração/criação dos documentos oficiais que regem o currículo das escolas públicas brasileiras está à disposição de criar formas de se trabalhar com o conhecimento regido pelos interesses dos poderosos e não com o interesse de trabalhar um conhecimento poderoso. Este último representa um perigo para a sociedade desde que o capitalismo se tornou o modo de produção dominante.

Podemos pensar que as críticas do governo brasileiro quanto à educação, na verdade, são meras desculpas para servir aos interesses de uma parcela dos poderosos da sociedade, pois, o que significa retirar de pauta algumas questões de relevância ao aprendizado? As questões de gênero, por exemplo, no mundo atual em que vivemos, onde sujeitos são julgados por suas escolhas, por sua orientação sexual ou por questões inerentes, como: 
raça, religião, origem étnica, etc., é necessário se abordar tais temas dentro das escolas para que o estudante desenvolva a tolerância e a compreensão do outro eu, diferente dele. Nas duas primeiras versões da BNCC foram pensadas e trazidas como discussão esses temas, porém, na terceira e atual versão aprovada e sancionada por lei, retiraram-se a palavra gênero. Isso ocorre devido à troca de governos. Até 2016, tinha se pensando em uma proposta, a partir do momento do impeachment, os interesses passam a ser outros, muda-se a proposta disfarçando o discurso.

Em concomitância aos objetivos e aos interesses que se sobressaem na BNCC, buscamos respaldo em Peroni \& Caetano $(2015$, p. 341; 348) quando elas afirmam que

A BNCC tornou-se um campo de disputas na educação brasileira em que diferentes sujeitos individuais e/ou coletivos vêm se articulando para buscar espaço em uma área fundamental da educação e da escola: o currículo. A disputa pelo currículo torna-se importante, pois nele pode ser impresso o conteúdo e a direção a ser dada à educação e à escola (...) A BNCC pode ser um instrumento de maior democratização do conhecimento, ou, ao contrário, um engessamento, com propostas vinculadas ao mercado, dependendo dos sujeitos e das correlações de forças envolvidos no processo.

Através disso, podemos dizer que o currículo escolar não é pensado enquanto possibilidade de desenvolvimento do conhecimento, da interpretação, mas é pensado por um grupo de profissionais, que, muitas vezes, não têm nenhum vínculo com a área da educação, pode ser qualquer profissional que tenha "conhecimento suficiente" para tratar de tais teorias. Estes atendem à demanda do mercado, que é formar sujeitos passivos de sua condição, aqueles que se "conformam" com o pouco que lhe é ofertado. As chamadas parcerias com a educação financiam uma política de educação e a divulgam como se fosse em prol de uma escola pública de qualidade.

Infelizmente, a elaboração da última versão da BNCC perdeu o seu sentido de qualificar a educação e ganhou outra direção oposta. Portanto, a afirmação de que os princípios éticos, políticos e estéticos são os orientadores dela e que juntos, eles visam a formação humana integral, é falho, equívoco. Nossa leitura é de que a formação humana integral a que ela remete não é em relação ao conhecimento, e sim, em relação à formação de sujeitos 
assujeitados por um sistema capitalista, de um sujeito que não se revolta e não questiona o seu papel, ele apenas cumpre aquilo que lhe é dito (cf. PÊCHEUX, 1997).

Assim, perguntamos qual seria a formação humana integral a que se refere a BNCC partindo dos princípios éticos, políticos e estéticos? Compreendemos que formação humana integral está em concomitância ao exercício de cidadania do sujeito e é o que a BNCC propõe em determinados momentos, que se trabalhe o conhecimento numa perspectiva democrática e cidadã. No entanto, conforme analisamos, não é dentro dessa perspectiva que a BNCC considera se pensar, de se formar um sujeito cidadão crítico e reflexivo numa sociedade marcada por relações de poder. O objetivo é que o sujeito continue dominado por tais forças.

Salientamos que essa falha decorre no processo de reescrita das duas primeiras versões para a última, ou seja, em vez de se propor uma continuidade nas discussões e preocupações que, em tese, levaram a se pensar na elaboração de uma base curricular comum orientadora da educação básica, o que se fez foi uma desconstrução de tais ideias, reformulando o contrário daquilo que deu início à tal proposta. Isso se comprova no momento em que a equipe designada para editar a última versão desconsidera as duas primeiras. Claro que não entraremos nesses detalhes, mas, é importante trazer como reflexão e questionamento. Continuamos explorando esses efeitos de sentido por outra sequência que se repete dentro do texto da BNCC, que é em relação às aprendizagens essenciais.

\subsection{Sobre as aprendizagens essenciais}

Na primeira página de introdução da BNCC já observamos que "aprendizagens essenciais" aparece em negrito. Assim, perguntamo-nos: o que significa aprender dentro desse contexto? O que pode ser compreendido como aprendizagens essenciais? Será que há limites em aprender? Qual é o efeito de sentido produzido ao designar o termo essencial para o aprendizado? E por que há necessidade em negritar tais palavras?

De acordo com Boufleuer \& Fensterseifer (2018), a espécie humana se constitui pedagogicamente. Isso permite dizer que o pedagógico constitui a nossa história, somos 
sujeitos em processo de construção porque há um pedagógico a nos orientar. Enquanto professoras, compreendemos que "pedagógico" diz respeito ao modo como ensinamos, às ferramentas e às metodologias utilizadas em aula para possibilitar que haja aprendizagem. Se considerar a heterogeneidade de sujeitos que frequentam a escola, como iremos determinar o que pode ser essencial no seu processo de formação? Iremos "medir" o grau de importância para o currículo escolar? São muitas as perguntas que podemos fazer diante dessa referência da BNCC.

Um dos efeitos de sentido que se produz diante da designação "aprendizagens essenciais" nos remete a uma limitação de conhecimentos, parece que se reduz a capacidade de aprendizagem do sujeito. Dito de outra forma, é como se fosse possível ensinar apenas o mínimo dos conteúdos escolares porque é eliminado aquilo que não se considera como essencial. $\mathrm{Na}$ área de linguagens, é difícil se pensar em essencial, pois não há divisórias de conteúdos isolados, ensinamos a ler e a interpretar o mundo. Portanto, não se pode dizer o que é ou não é importante. Há uma retomada, nesse sentido, do momento histórico do positivismo, o qual já foi abordado anteriormente neste artigo. Vimos que nesse movimento, o sujeito era induzido pela explicação da ciência, não se mencionava o pensamento crítico. Emerge o desejo de retomar essa parte da história onde é relevante apenas o científico.

Neste contexto, novamente estamos diante de um equívoco descrito pela BNCC quando a referência é o processo de formação cidadã e autônoma do sujeito. Se considerar o positivismo, não há formação de sujeitos ativos na sociedade, mas, sim, de sujeitos passivos, que só recebem o que já está pronto, sem espaço para questionamentos. Através desse método de ensino, se torna difícil imaginar o lugar da área das linguagens, posto que, para essa área do conhecimento, não há respostas prontas e exatas, o sujeito interpreta e se posiciona para formar uma visão de mundo. Ela também opera com uma noção do conhecimento inacabado, ou seja, dificilmente se chega a uma conclusão, sempre há possibilidades de respostas. 
Ao pesquisar o significado de essencial, no dicionário (HOUAISS, 2009, p. 826), encontramos o seguinte

1 que é inerente a algo ou alguém 2 que constitui o mais básico ou o mais importante em algo; fundamental 3 que é necessário, indispensável 4 diz-se de aminoácido cuja síntese não é possível pelo organismo dos seres humanos, e que deve ser obtido através dos alimentos $\mathbf{5}$ da natureza da essência $\mathbf{6}$ diz-se da doença que existe por si mesma, não causada pela coexistência de outras 7 a coisa principal; o indispensável.

Todas as descrições de essencial apontam para o básico, fundamental, o mais importante... O que poderia ser mais importante em termos de aprendizagem? Se pensar em didática, até podemos selecionar partes de um mesmo conteúdo para contribuir que aconteça aprendizado com sucesso, porém, não iremos dispensar outros conteúdos por julgar não ser importantes. É muito difícil, enquanto sujeito professora da educação básica, pensar em "cortar" noções de conteúdos para trabalhar em sala de aula.

Além disso, se fizer uma distinção entre o que é importante com aquilo que não é, estaríamos desconsiderando novamente as diferentes situações de aprendizagem. É comum ouvir de professores, principalmente de matemática, não ter "vencido" o conteúdo programado para ensinar naquele ano letivo. Esse discurso ancorado na visão de que é preciso seguir conteúdos programáticos e dar conta deles, não releva a qualidade do aprendizado, se preocupa apenas com a quantidade "despejada" para o aluno. Talvez toda aquela lista de conteúdos trabalhados durante o ano letivo não faça sentido nenhum para quem está aprendendo. A pergunta que emerge é: para que devo aprender isto? Qual será a utilidade disso para minha vida?

Observando esses questionamentos levantados em uma sala de aula, não podemos desconsiderar que de certa forma os sujeitos alunos têm razão, há um olhar de sensibilidade para o que está sendo ensinado. A escola deveria repensar o currículo, não se preocupar apenas com o "essencial" e buscar alternativas para uma educação que permita ampliar os horizontes acerca daquilo que se ensina, afinal, nem todos os sujeitos atribuem o mesmo sentido para aquilo que aprendem, depende muito do lugar em que estão inseridos e das 
suas tomadas de posição mediante o mundo. Nessa perspectiva, Fensterseifer (2013, p. 126) destaca que

no interior da escola todos os componentes curriculares respondem pelo caráter republicano (público) desta instituição no modo como lidam com o conhecimento e com as relações sociais que acontecem neste espaço. O que implica, em primeiro lugar, não se limitar a reproduzir os sentidos/significados encarnados pelas diferentes manifestações culturais, mas tematizando-os, desnaturalizá-los, evidenciando a pluralidade de sentidos/significados que os sujeitos podem produzir nos mais variados contextos. Pluralidade que só instituições com esse caráter republicano podem preservar e que não são necessariamente compatíveis com os marcos de outros modos humanos de organizar a vida em sociedade.

A partir dessa explicação, ressaltamos que os conteúdos escolares não devem ser levados ao "pé da letra", isto é, não podemos, enquanto sujeito professores da educação básica, inseridos numa escola pública, de caráter democrático, cair na ilusão de que devemos ensinar tudo o que está pronto, mas, devemos ensinar o sujeito aluno a tomar posicionamento, a repensar aquilo que está reproduzido na sociedade, permitindo que ele atribua significados, compreenda a sua relação com a história no mundo. No momento em que a BNCC trata das diferentes aprendizagens como "essenciais", ela omite ou nega esta possibilidade de questionar, de debater aquilo que se ensina ou se aprende.

Poderíamos analisar muito mais e trazer outras questões que chamam atenção dentro desse documento que rege a educação básica, porém, tivemos que delimitar a pesquisa para realizar esse trabalho. Em outro momento, se possível, daremos continuidade em retomar esses estudos e a investigar outras pistas linguísticas. Por ora, vejamos o desfecho das nossas ideias.

\section{Considerações finais}

Nossas análises não se esgotam até o presente momento, tentamos apenas demonstrar alguns dos possíveis efeitos de sentido a que somos remetidas diante das palavras que mais se destacam dentro da BNCC, seja pela frequência com que aparecem ou pela demarcação em negrito. Podemos dizer que a escolha de tais palavras é em função do nosso olhar 
de analistas do discurso, inquietas e inconformadas pelo descaso brasileiro com a educação pública. Sabemos que a BNCC não é um documento apenas para as escolas públicas, ela é uma normativa para a educação básica, tanto pública quanto privada. Porém, ao escrever descaso com a educação pública é pelo fato de que o espaço privado da educação tem outra organização independente de leis, mesmo que ainda seja obrigada a seguir um parâmetro curricular comum.

O levantamento de alguns fatos históricos que contribuíram para elaborar a BNCC chamou atenção pelo período de tempo em que a educação pública brasileira esteve fora do alcance da camada pobre da população. De acordo com o sistema político, a educação podia ou não ser prioridade. $\mathrm{Na}$ maioria das vezes ela não era pensada para todos, era privilégio da elite, uma minoria brasileira que copiava os moldes europeus. Assim, o principal objetivo que acompanhou e provavelmente ainda acompanha os documentos oficiais da educação pública brasileira não é formar bases para o conhecimento poderoso. O que se almeja é um conhecimento para os poderosos (cf. YOUNG, 2007).

Embora a BNCC represente uma conquista em termos de cidadania e de direitos adquiridos para uma educação pública e de qualidade, estando amparada por outras leis anteriores, como, por exemplo, a Constituição Federal de 1988 que garante o direito universal de acesso à escola, para todos e sem distinção, os PCNs e outras leis que já mencionamos ao longo desta pesquisa, não podemos deixar de observar que também há falhas e equívocos dentro dela. As análises permitiram compreender que há uma retomada de abordagens de ensino fracassadas, dentre elas, o positivismo.

As noções teóricas da $\mathrm{AD}$ que mobilizamos para análise trazem à tona que há um processo de interpelação ideológica, o sujeito é levado a acreditar na proposta de que a BNCC seria um excelente referencial para a educação. As investigações mostraram que há uma comparação com os melhores países do mundo, tentando alinhar a proposta brasileira com aqueles que detêm os primeiros lugares no ranking em educação. Desse modo, há um imaginário de que seria fácil e simples mudar a nossa realidade chegando rapidamente às 
mesmas condições das escolas daqueles países que têm turno integral para a educação básica. Conforme explicamos no decorrer desta pesquisa, não há infraestrutura adequada dentro das nossas escolas, faltam recursos financeiros (investimentos) para ampliação do espaço, aquisição de materiais e projetos fundamentados para esse fim.

Além disso, há um embate de ideias dentro do texto da BNCC, é o político da língua que entra em funcionamento. O recorte para o processo de análises possibilitou compreender que os seus princípios fundamentadores éticos, políticos e estéticos produzem efeitos de sentido voltados a uma abordagem de ensino que não considera a formação de sujeitos críticos. O objetivo é que o sujeito continue passivo à sua condição para não se revoltar contra o sistema capitalista vigente na sociedade, evitando alterar o percurso da história, o qual determina que somente uma pequena parcela da população tenha acesso ao ensino de qualidade estendendo os seus estudos para uma graduação, pois isso garante que quem está no poder continue dominando os que não tiveram as mesmas oportunidades.

A outra parte do recorte, no que concerne às aprendizagens essenciais, remete a uma abordagem de ensino positivista, que reduz o pensamento crítico e prevê somente o aprendizado através de explicações fundamentadas em métodos científicos. Nesse caso, a área das linguagens torna-se desvalorizada, já que ela opera com a interpretação, com a possibilidade de respostas inacabadas, sempre há espaço para questionamentos e resistências.

Enquanto sujeito professoras da educação básica, acreditamos que é preciso trabalhar numa perspectiva crítica, não podemos estar limitadas ao que descreve a BNCC. Ao mesmo tempo em que ela é importante, sendo uma conquista na área da educação, também há questões que ela aborda para repensar. Nossa função é de estar atentas a tais propostas e "desmascarar" aquilo que não se enquadra em nosso anseio de buscar a qualidade e valorização da escola pública. Somos responsáveis em continuar esta luta. 


\title{
DISCURSIVE ANALYSIS ON BNCC: CONSTRUCTION OR (DE)CONSTRUCTION OF BRAZILIAN PUBLIC SCHOOL EDUCATION?
}

\begin{abstract}
The interest to develop this work emerge by the approval of the Curricular Commom National Base (BNCC) instituted as reference for the Brazilian schools of basic education. Although it has been a conquest in terms of respect to the laws that conduct the Brazilian education, we also can affirm there are many non-explicit questions inside him, wich just can be understood by an analytical reading. We will analyze some passages of this document sensitizing for the meanings effects production that are produced in determined contexts of language use. For this, we take as theoretical reference the Discourse Analyses (DA) of French line, mobilizing notions as ideology, discourse and materialism historic and authors like: Michel Pêcheux and Eni Orlandi. Our analysis show that the politic of language enter in play and operate with different meanings that seem to be different when we do a superficial reading of this document conducted by the common sense. Thus, we organize the structure of this work in the following way: after the introductory considerations, we highlight some theoretical notions of DA that will be approached throughtout the research. In the sequence, we summarize the historical part of the education official documents elaboration that came before the BNCC emphasizing the language is inscribed in the history. So, we start the analysis and trace a brief conclusion of these studies.
\end{abstract}

KEYWORDS: Curricular Common National Base; school education; ideology; meanings effects and language politic.

\section{REFERÊNCIAS}

BOUFLEUER, José Pedro \& FENSTERSEIFER, Paulo Evaldo. O sujeito do conbecimento $e$ a aprendizagem. No prelo.

CLARK, Jorge Uilson. As escolas protestantes paulistas durante o periodo de renovação da educação brasileira (1930-1945). Campinas: 2003. Tese (Doutorado em Educação) - UNICAMP, 2003. Texto extraído de: http://www.histedbr.fe.unicamp.br/navegando/periodo_pombalino_arquivos.html. Acesso em 17/09/2018.

FENSTERSEIFER, Paulo Evaldo. Função da Escola Pública. In: Anna Rosa Fontella Santiago; Iselda Teresinha Sausen Feil; Lídia Inês Alebrandt. (Org.). O curso de Pedagogia da Unïui 55 anos. 1ed. Ijuí / RS: Unijuí, 2013, v. 1, p. 123-147.

HERMANN, Nadja. Ética \& educação: outra sensibilidade. Belo Horizonte: Autêntica Editora, 2014.

HOUAISS, Antônio. Dicionário Houaiss da lingua portuguesa. Rio de Janeiro: Objetiva, 2009. 
MACHADO, Maria Cristina Gomes; KASTELIC, Eloá Soares Dutra. Paschoal Lemme e as reformas educacionais de 1930: uma discussão sobre a formação de professores. Texto disponível em: http://www.histedbr.fe.unicamp.br/navegando/artigos_frames/artigo_039.html. Acesso em 15/10/2018.

MASSCHELEIN, Jan; SIMONS, Maarten. Em defesa da escola: uma questão pública. Tradução Cristina Antunes. 2. ed., Belo Horizonte, Autêntica Editora, 2014.

NASCIMENTO, Maria Isabel Moura. O império e as primeiras tentativas de organização da educação nacional (1822-1889). Texto disponível em: http:/ / www.histedbr.fe.unicamp.br/navegando/periodo_imperial_intro.html. Acesso em 20/10/2018.

ORLANDI, Eni P. Análise de discurso: princípios e procedimentos. Campinas, SP: Pontes, 1999.

. Discurso, imaginário social e conhecimento. Em Aberto, Brasília, ano 14, n.61, p. 52-59, jan.-/mar.1994.

PÊCHEUX, Michel. Semântica e discurso: uma crítica à afirmação do óbvio. 3.ed. Traduzido por Eni P. Orlandi [et.al.]. Campinas, SP: Editora da Unicamp, 1997.

PERONI, Vera Maria Vidal; CAETANO, Maria Raquel. O público e o privado na educação. Projetos em disputa? Retratos da Escola, Brasília, v. 9, n. 17, p. 337-352, jul./dez. 2015.

SAVIANI, Dermeval. As concepções pedagógicas na história da educação brasileira. Texto disponível em: http://www.histedbr.fe.unicamp.br/navegando/artigos_frames/artigo_036.html. Acesso em 15/11/2018.

SECO, Ana Paula \& AMARAL, Tania Conceição Iglesias do. Marquês de Pombal e a reforma educacional brasileira. Texto disponível em: http://www.histedbr.fe.unicamp.br/navegando/periodo_pombalino_intro.html. Acesso em 17/09/2018.

TEIXEIRA, Olga Suely; CORDEIRO, Rubério de Queiroz. Educação Jesuíta: objetivo, metodologia e conteúdo nos aldeamentos indígenas do Brasil Colônia. Anais do II Encontro Internacional de História Colonial. Mneme - Revista de Humanidades. UFRN. Caicó (RN), v. 9. n. 24, Set/out. 2008.

YOUNG, Michael. Para que servem as escolas? Educação e Sociedade. Campinas, vol. 28, n. 101, p. 1287-1302, set./dez. 2007.

Recebido em: 31/05/2019.

Aprovado em: 31/07/2019. 